\title{
Testing of Microalloyed Steel Quality under Creep Conditions for a New Intended Use
}

\author{
Mária Mihaliková, Kristína Zgodavová, and Anna Lišková \\ Institute of Materials, Faculty of Metallurgy, Technical University of Košice, Letná 9, 04002 Košice, Slovakia \\ Correspondence should be addressed to Mária Mihaliková; maria.mihalikova@tuke.sk
}

Received 11 April 2017; Revised 8 June 2017; Accepted 14 June 2017; Published 18 July 2017

Academic Editor: Patrice Berthod

Copyright (C) 2017 Mária Mihaliková et al. This is an open access article distributed under the Creative Commons Attribution License, which permits unrestricted use, distribution, and reproduction in any medium, provided the original work is properly cited.

\begin{abstract}
The paper deals with the testing of microalloyed steels H300LAD and H380LAD under creep conditions. To test the properties of these steels, tensile and creep tests were carried out in the temperature range of $200-500^{\circ} \mathrm{C}$. Torn samples were subjected to microscopic and submicroscopic observations. Microalloyed steels were compared with the alloyed steels C16E and 16Mo3 bypasses used at the same temperatures. The results of the experiments highlighted the possibility of application of microalloyed steels in operations within the specified temperature range.
\end{abstract}

\section{Introduction}

Increasing the strength properties of traditional carbon steels is possible only by increasing either the carbon or manganese content in steel, which caused expressive significant decrease of brittle fracture and technological properties (weldability, flexibility). Alloying of low carbon steels, mainly using Nb, $\mathrm{V}$, Ti (up to $0.15 \%$ ), or other elements, in combination with thermomechanical processing, enables the obtaining of microalloyed steels; using especially grain and precipitation hardening, the high values of yield stress, up to $600 \mathrm{MPa}$, were attained, whereas the mechanical and technological properties were the same or even better [1]. Microalloyed steel is a type of alloy steel that contains small amounts of alloying elements $(0.05$ to $0.15 \%)$, including niobium, vanadium, titanium, molybdenum, zirconium, boron, and rare-earth metals. They are used to refine the grain microstructure or to facilitate precipitation hardening [2]. Microalloyed steels, which, according to [3], are noted as being nonalloyed highgrade steels, have been developed with the aim of enhancing strength properties while maintaining, or further improving, strength properties compared to usual steel grades $[4,5]$. By modifying their chemical compositions, and the technology of thermomechanical treatments, their properties can be optimized for various fields of application.
These materials offer economic, environmental, and social benefits, when compared to the more commonly used steel grades, through a reduction in material usage, weight, and section size [6].

In order for the final product to be properly developed and applied, a number of factors must be considered when manufacturing individual components, including design, processes, inspection, and quality control of the structure [7].

The quality of steel can be defined, according to [8], as an inherently quantifiable attribute that is used to determine steel's ability to perform its designed function without limitations due to internal flaws or significant variances in microstructure or homogeneity.

It is especially important to realize the examination of the quality of a material in relation to its purpose. The aim of this paper is to research the influence of temperature, ranging from $200^{\circ} \mathrm{C}$ to $500^{\circ} \mathrm{C}$, on the strength and failure processes of microalloyed steels, considering the possibilities of application in constructing power equipment working at elevated temperatures of up to $500^{\circ} \mathrm{C}$.

To determine the resistance of the examined materials to high temperatures, we have used a test procedure according to ISO 6892-1:2009 [9] and ISO 6892-2:2011 [10], at elevated temperatures, up to $500^{\circ} \mathrm{C}$. The samples of the investigated materials were tested under creep conditions at the same 


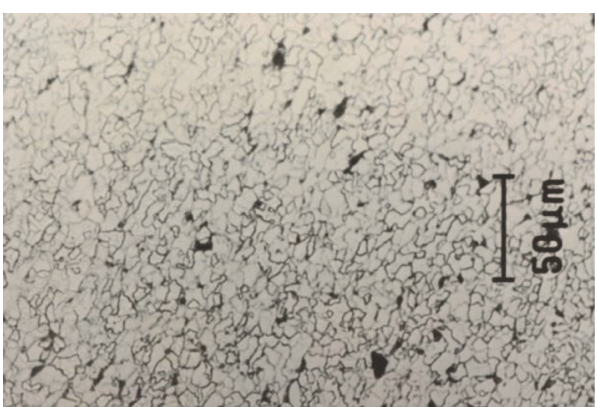

(a)

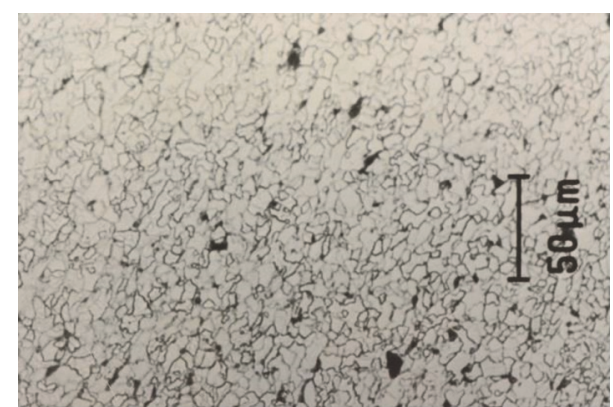

(b)

Figure 1: Microstructure microalloyed steels (a) H300LAD and (b) H380LAD.

TABLE 1: Chemical composition of tested microalloyed and standardly-used steels.

\begin{tabular}{lccccccccccc}
\hline Material & $\begin{array}{c}\mathrm{C} \\
\text { wt. [\%] }\end{array}$ & $\begin{array}{c}\mathrm{Mn} \\
\text { wt. [\%] }\end{array}$ & $\begin{array}{c}\mathrm{Si} \\
\text { wt. [\%] }\end{array}$ & $\begin{array}{c}\mathrm{P} \\
\text { wt. [\%] }\end{array}$ & $\begin{array}{c}\mathrm{S} \\
\text { wt. [\%] }\end{array}$ & $\begin{array}{c}\text { Al } \\
\text { wt. [\%] }\end{array}$ & $\begin{array}{c}\text { Ti } \\
\text { wt. [\%] }\end{array}$ & $\begin{array}{c}\text { Nb } \\
\text { wt. [\%] }\end{array}$ & $\begin{array}{c}\text { V } \\
\text { wt. [\%] }\end{array}$ & $\begin{array}{c}\text { Mo } \\
\text { wt. [\%] }\end{array}$ & $\begin{array}{c}\text { Cr } \\
\text { wt. [\%] }\end{array}$ \\
\hline H380LAD & 0.007 & 0.860 & 0.020 & 0.011 & 0.005 & 0.037 & 0.013 & 0.038 & 0.003 & - \\
H300LAD & 0.008 & 0.730 & 0.020 & 0.013 & 0.004 & 0.028 & 0.009 & 0.039 & 0.005 & - \\
C16E & 0.150 & 0.500 & 0.150 & 0.040 & 0.040 & 0.150 & - & - & - & - \\
16Mo3 & 0.120 & 0.500 & 0.150 & 0.040 & 0.040 & 0.150 & - & - & - & 0.300 & - \\
\hline
\end{tabular}

temperatures. Torn samples were subjected to microscopic and fractographic analyses in order to determine the prevailing degradation mechanisms.

The reason for examining the resistance of microalloyed steels to high temperatures is because of their potential use in industrial practices, as a high-temperature protection shields for pipelines.

\section{Material Descriptions}

To determine the suitability of using microalloyed steels in operation at elevated temperatures, two types of microalloyed steel, H380LAD and H300LAD, were tested, and their characteristics were then compared to those of two alloyed steels, $\mathrm{C} 16 \mathrm{E}$ and $16 \mathrm{Mo} 3$.

The structure of microalloyed steels consisting of a substitution-hardened, fine-grained matrix and fine, uniformly distributed precipitates in the matrix provides the precondition that their properties at elevated temperatures will be better than those of usual creep-resisting steels [11].

Figure 1(a) shows the microstructure of microalloyed steels H 300LAD and Figure 1(b) shows the microstructure of microalloyed steels $\mathrm{H}$ 380LAD.

Microalloyed steels are characterized by a ferrite-pearlite fine-grained structure with small quantities (max. 0.15\%) of a combination of $\mathrm{Al}, \mathrm{Ti}, \mathrm{Nb}$, and $\mathrm{V}$; these elements are bound to $\mathrm{C}$ and $\mathrm{N}[11,12]$. The microalloying effects are related to the solubility of carbides (TiC, $\mathrm{NbC}$ ), nitrides (TiN, AlN), and carbonitrides of Ti in austenite and ferrite [13].

An increase in strength characteristics can be obtained using grain refinement and precipitation. Current high strength steels mean "steels with a nominal yield stress equal to or above $550 \mathrm{MPa}$." The mechanical properties of the microalloyed steels are largely provided by the type of microstructure, which depends on the chemical composition and processing technology [14].

Experimental tests were performed on the cold rolling samples prepared from strips of steels with a thickness of $8 \mathrm{~mm}$. All samples were cut in the rolling direction. The chemical compositions of the steels are given in Table 1.

2.1. Thermomechanical Treatment. Thermomechanical processing is a metallurgical process that combines mechanical and plastic deformation process. Thermomechanical processing is an effective method for ferrite grain refinement in microalloyed steels [15]. The microalloyed steels were held on the temperature of $1260^{\circ} \mathrm{C}$ for $30 \mathrm{~min}$ and rolled on continuous tandem with reduction $30 \%$ longer than $1 \mathrm{~s}$. The final phases are in the ferrite temperature range. Warm rolling of investigated steels produces ferrite and precipitation of microalloying elements.

\section{Methodology}

The testing process was carried out on microalloyed steel samples, H380LAD and H300LAD, according to ISO 68922:2011 [10], at elevated temperatures, as follows: (1) sample preparation $\rightarrow$ (2) performance of the tests $\rightarrow$ (3) sample analysis $\rightarrow$ (4) evaluation of the results.

3.1. Sample Preparation. Tested samples were prepared according to the standard ASTM A370 test method, and round bars were made $(d=6 \mathrm{~mm})$ for tensile and creep tests. Tensile testing at the specified strain rates was carried out using a Zwick 1387 servo-hydraulic testing machine (load capacity of $1000 \mathrm{kN}$ and load weighing accuracy of $\pm 0.005 \%$ load capacity). 
TABLE 2: Tensile testing under static conditions at elevated temperatures.

\begin{tabular}{|c|c|c|c|c|c|c|c|c|}
\hline \multirow{3}{*}{${ }^{1} T$} & \multicolumn{8}{|c|}{ Material } \\
\hline & \multicolumn{2}{|c|}{ H300LAD } & \multicolumn{2}{|c|}{ H380LAD } & \multicolumn{2}{|c|}{$16 \mathrm{Mo} 3$} & \multicolumn{2}{|c|}{$\mathrm{C} 16 \mathrm{E}$} \\
\hline & ${ }^{2} R_{e}$ & ${ }^{3} R_{m}$ & $R_{e}$ & $R_{m}$ & $R_{e}$ & $R_{m}$ & $R_{e}$ & $R_{m}$ \\
\hline 20 & 301 & 425 & 385 & 492 & 270 & 450 & 215 & 390 \\
\hline 200 & 297 & 444 & 363 & 496 & 255 & 421 & 202 & 372 \\
\hline 300 & 273 & 403 & 282 & 460 & 203 & 402 & 183 & 351 \\
\hline 350 & 253 & 363 & 246 & 452 & 196 & 351 & 171 & 322 \\
\hline 400 & 242 & 359 & 257 & 425 & 185 & 346 & 152 & 285 \\
\hline 450 & 202 & 303 & 229 & 374 & 177 & 302 & 142 & 268 \\
\hline 500 & 190 & 250 & 204 & 328 & 167 & 272 & 131 & 232 \\
\hline
\end{tabular}

${ }^{1} T$ : temperature $\left({ }^{\circ} \mathrm{C}\right) ;{ }^{2} R_{e}$ : yield strength (MPa); ${ }^{3} R_{m}$ : ultimate strength (MPa).

3.2. Test Realization. The tensile test was initially carried out at room temperature $\left(20^{\circ} \mathrm{C}\right)$ according to ISO 6892-1:2009, and at elevated temperatures, in the range of $200-500^{\circ} \mathrm{C}$, according to ISO 6892-2:2011. The results are shown in Table 2 and were used to determine the tension $\left(R_{0}\right)$ for the creep test at relevant temperatures.

Uniaxial creep testing in tension involves a tensile specimen under a constant load at a constant temperature. Stress rupture testing is like creeps testing aside from the stresses being higher than those utilized within a creep testing. Stress rupture tests are utilized to find out the time it takes for failure, so stress rupture testing always continues until failure of the material occurs. The stress rupture test is used to determine the time to failure. Creep testing at the specified strain rates and temperature is carried out using HTC-50B Stress Rupture and Creep Testing Machine.

Then, creep tests were performed according to ISO 204:2009 [16]. The results were calculated as the time to stress rupture $-R_{m T}$.

To assess the creep properties of alloyed steels, stress rupture tests were performed. The duration of the tests was between $10^{2}$ and $10^{4}$ hours.

3.3. Analyses of Samples. For metallographic analysis of the microstructure of fracture surface, an Olympus optical microscope (Vanox-TAH2) was used. The test results are shown in Figures 8(a) and 8(b).

For a detailed analysis of the samples, metallographic analysis using a scanning electron microscope (JEOL JSM35CF) was used. Test results are shown in Figures 9(a) and 9(b).

The patterns of microalloyed steels precipitates (Figures 10(a) and 10(b)) were obtained using a transmission electron microscope (JEOL-2000FX).

The specimens for microstructural studies were mechanically polished using standard metallographic procedures (according ASTM E3-11 Standard Guide for Preparation of Metallographic Specimens) and were etched with a 4 vol.\% Nital solution.

\section{Results}

4.1. Results of Creep Tests. The results of the creep test are the determination of the time to fracture $\left(t_{f}\right)$ and the dependence

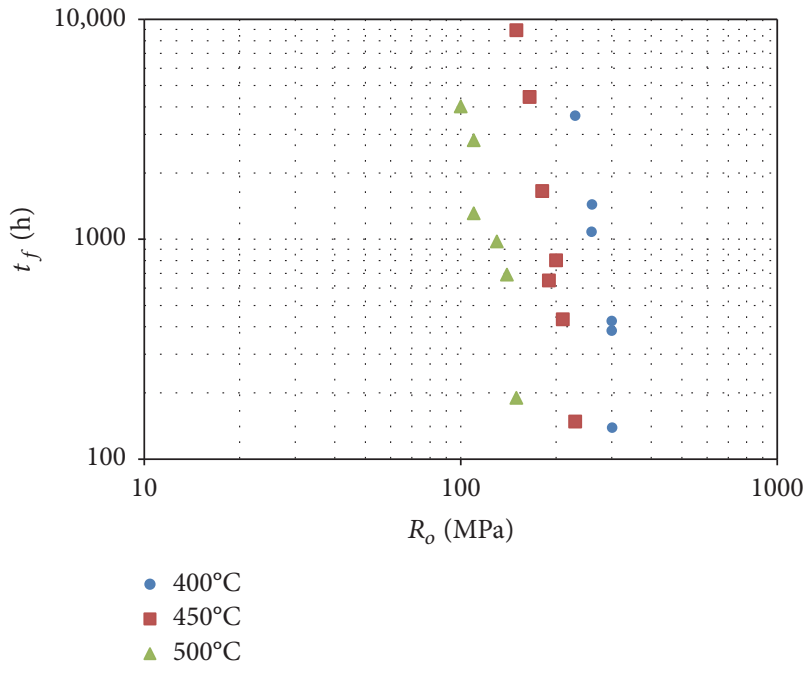

Figure 2: Dependence of the time to fracture $\left(t_{f}\right)$ on the nominal stress $\left(R_{o}\right)$ for H300LAD steel.

on nominal stress $\left(R_{o}\right)$ (Figures 2 and 3 ). The creep limit $\left(R_{m T} 10^{4}\right)\left(R_{m T}\right.$ - creep rupture strength) was determined via extrapolation. $R_{m T} 10^{4}$ values of the tested steels, at $400^{\circ} \mathrm{C}$, $450^{\circ} \mathrm{C}$, and $500^{\circ} \mathrm{C}$, and the selected creep-resistant steels (C16E and 16Mo3) (according to material data sheets) are documented in Figure 4. The results in Figure 3 show that $R_{m T} 10^{4}$ values of the tested steels were higher than those of the carbon creep-resistant steel $(\mathrm{C} 16 \mathrm{E})$ but lower than those of the low-alloyed steel (16Mo3).

The creep limit to tensile strength ratio is considered to be a creep-resistance characteristic of steels $[17,18]$. Figure 5 shows the temperature function of this ratio for the tested steels and the selected creep-resistant steels. The ratio $R_{m T} / R_{m}$, characterizes the degree of resistance to creep tested steels. Carbon creep-resistant steels are usually used for temperatures up to $450^{\circ} \mathrm{C}$. At this temperature (Figure 5), the $R_{m T} 10^{4} / 450 / R_{m}$ ratio of the carbon steel is 0.25 , but for $\mathrm{H} 300 \mathrm{LAD}$ it is $28 \%$ higher, for $\mathrm{H} 380 \mathrm{LAD}$ it is $64 \%$ higher, and for $16 \mathrm{Mo} 3$ it is $140 \%$ higher. At $500^{\circ} \mathrm{C}$, this difference increases; for example, for H380LAD, this ratio is only $18 \%$ lower than that of $16 \mathrm{Mo}$. Thus, the precipitation hardening has a decisive effect on creep properties of microalloyed 


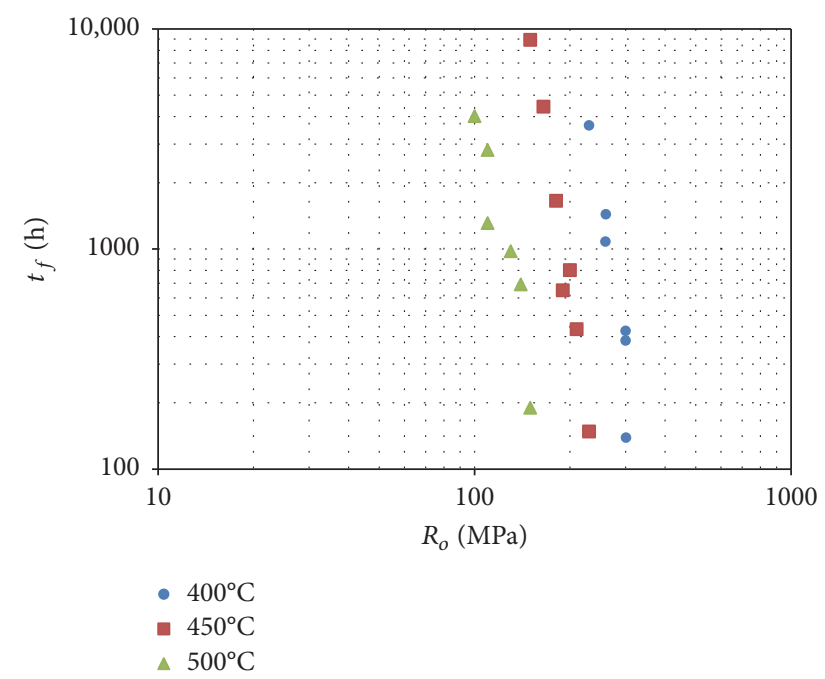

FIgURE 3: Dependence of the time to fracture $\left(t_{f}\right)$ on the nominal stress $\left(R_{o}\right)$ for H380LAD steel.

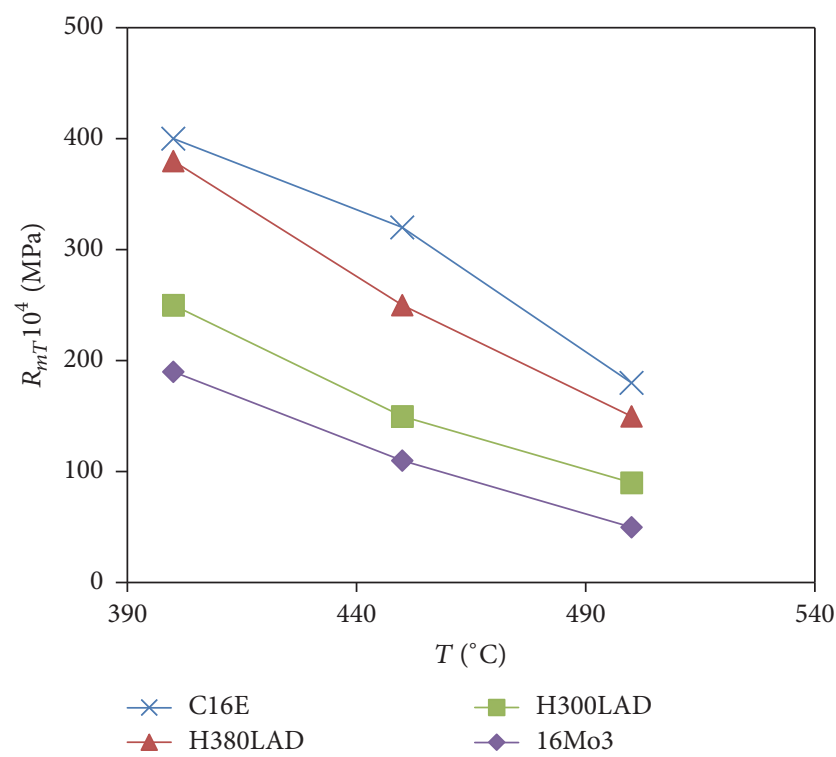

FIgURE 4: $R_{m T} 10^{4}$ temperature functions of tested steels and of selected creep-resistant steels.

steels. This work analyzes the particular hardening contributions participating in the $R_{e}$ value. Increased precipitation hardening of steel (H300LAD) is $8 \%$ and H380LAD is $24 \%$. Therefore, this steel has higher creep limit values, which approach the values of the low-alloyed creep-resistant steel, $16 \mathrm{Mo3}$.

\section{Analyses and Discussion}

Experiments showed that the microalloyed steels tested favorably under creep conditions. The failure development stages of metal materials during high-temperature loading do not differ from a common fracture process, which is characterized by gradual local and time accumulation of

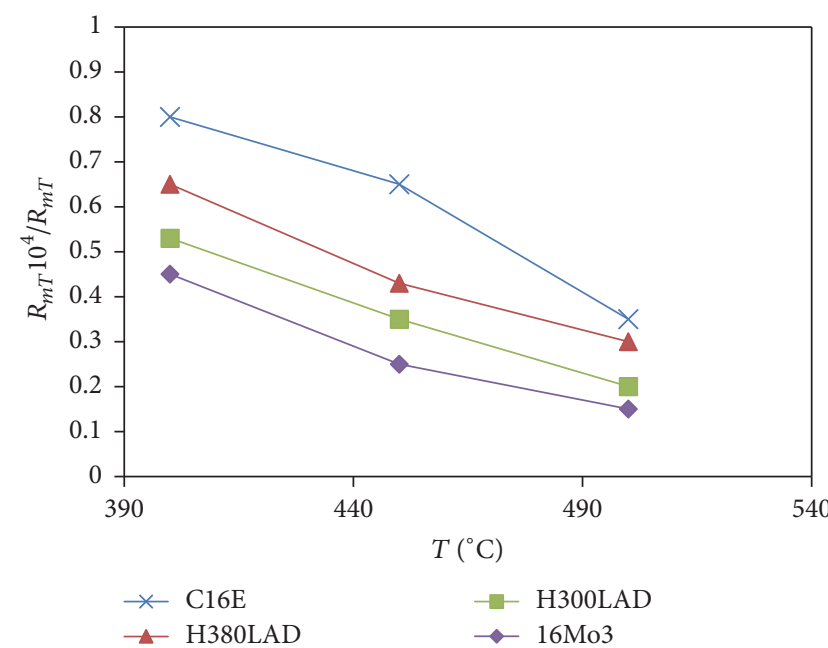

FIgURE 5: Ratio of $R_{m T} 10^{4}$ temperature function of tested steels and of selected creep-resistant steels.

individual forms of failure $[19,20]$. The characteristics of the failure of integrity and of fracture are functions of stress, temperature, and creep rate [21-23]. The creep rate, and, hence, the failure characteristic under constant stress and temperature are functions of the structure of steel. Figure 6(a) documents the fractures of $\mathrm{C16E}$ steel, and Figure 6(b) documents the fractures of H300LAD with various times to fracture. The fractures of $\mathrm{C} 16 \mathrm{E}$ steel have a cup characteristic, even at a time to fracture of $10^{4} \mathrm{~h}$; however, the fracture of H300LAD can be considered as brittle fractures from a macroscopic point of view at a time to fracture as short as $10^{3} \mathrm{~h}$. This is due to a significant decrease in the reduction of the area of microalloyed steels with an increase of fracture time, as shown in Figure 7. In Figure 7 is shown dependence of the contraction $(Z)$ on time to $\operatorname{crack}\left(t_{f}\right)$ of the tested steels at $450^{\circ} \mathrm{C}$.

The failure process of $\mathrm{C16E}$ steel is presented in Figure $8(\mathrm{a})$. The $\mathrm{C} 16 \mathrm{E}$ steel is significantly deformed before failure and lies within the entire range of the selected creep conditions (Figure $8(\mathrm{~b})$ ); its failure process is similar to the failure process in the tensile test (Table 2). The creep failure characteristics of the tested steels at a given temperature depend on the stress and the time to fracture (creep rate).

At fracture times, that is, under high stress, the fracture has a transcrystalline, or predominantly transcrystalline, character, as the high stress allows plastic deformation of the entire volume (Figures 9(a) and 9(b)). From the microscopic point of view, cup-shaped fractures were formed. At long fracture times and under low stress, deformation occurs, mainly in the area of grain boundaries, where failure is initiated and concentrated (Figures 10(a) and 10(b)).

The growth of $\mathrm{V}$-shaped cracks takes place due to slippage along grain boundaries, which results in an intercrystalline fracture. The substructure of H300LAD, with precipitation, is shown in Figure 10(a). Figure 10(b) shows that H380LAD steel precipitates are smaller and more dispersed.

Hardening by the grain boundaries, which represents a crucial contribution of hardening of microalloyed steels at 


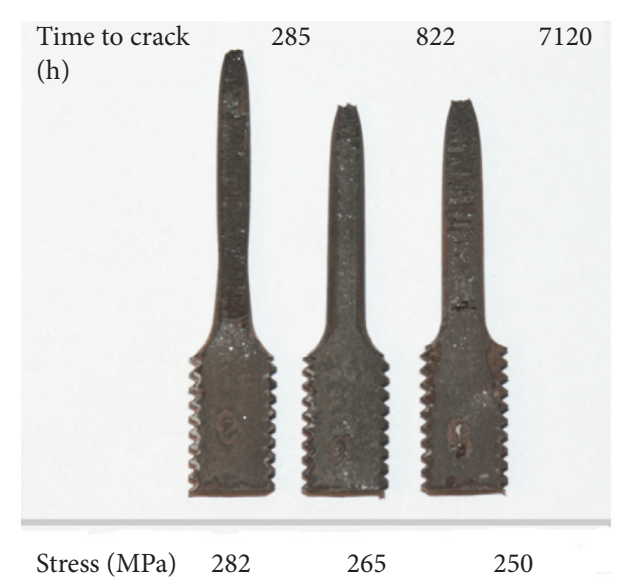

(a)

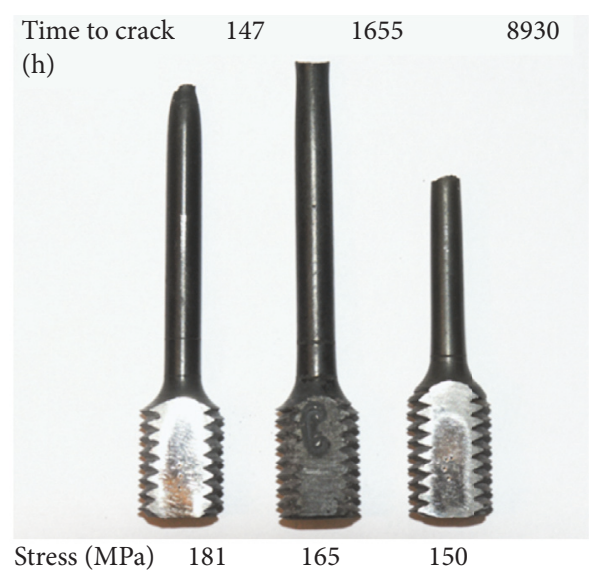

(b)

Figure 6: Fractures of steel. (a) Tensile specimens of C16E steel after creep exposition at $450^{\circ} \mathrm{C}$; (b) fracture of H300LAD steel after creep exposition at $450^{\circ} \mathrm{C}$.

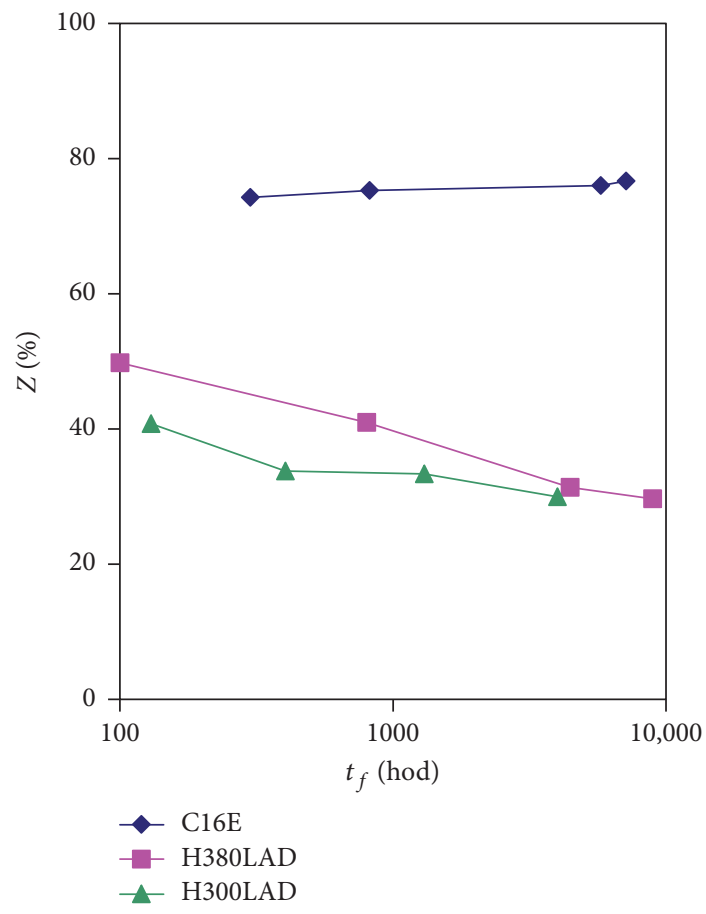

FIGURE 7: Dependence of the contraction $(Z)$ on time to crack $\left(t_{f}\right)$ of the tested steels at $450^{\circ} \mathrm{C}$.

higher temperatures (up to $500^{\circ} \mathrm{C}$ ) only, has an effect in short-time loading. In the creep conditions, the effect of this hardening on the stress rupture strength is neglected hardening.

\section{Conclusions}

This paper analyzes the influence of temperature, ranging from $200^{\circ} \mathrm{C}$ to $500^{\circ} \mathrm{C}$, on the strength and the failure processes of microalloyed steels and compares it to standard-use,

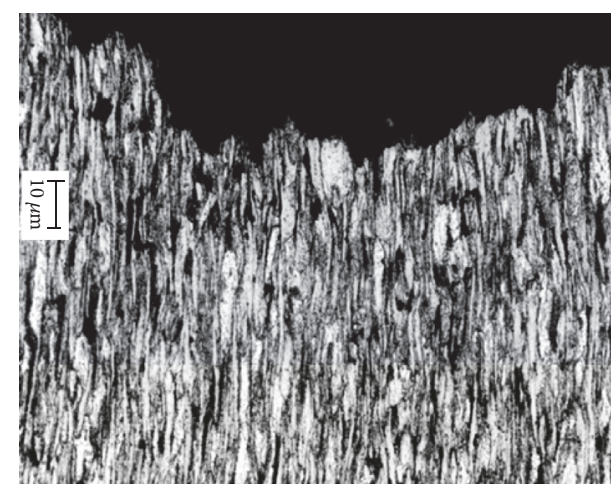

(a)

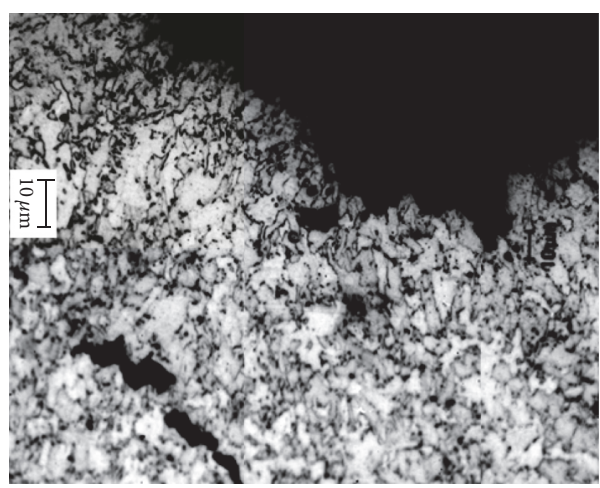

(b)

Figure 8: Close to fracture microstructure. (a) C16E after creep exposition at $450^{\circ} \mathrm{C}, 7120 \mathrm{~h}$; (b) H300LAD after creep exposition at $450^{\circ} \mathrm{C}, 8930 \mathrm{~h}$.

higher-quality alloyed steels. Based on the experiments and their analyses, the following can be stated:

(i) The failure characteristics of the tested microalloyed steels under creep conditions change depending on the fracture time. At short fracture times, cup-shaped 


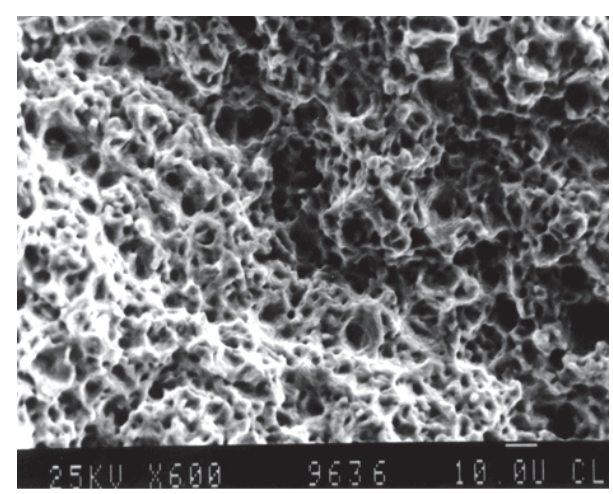

(a)

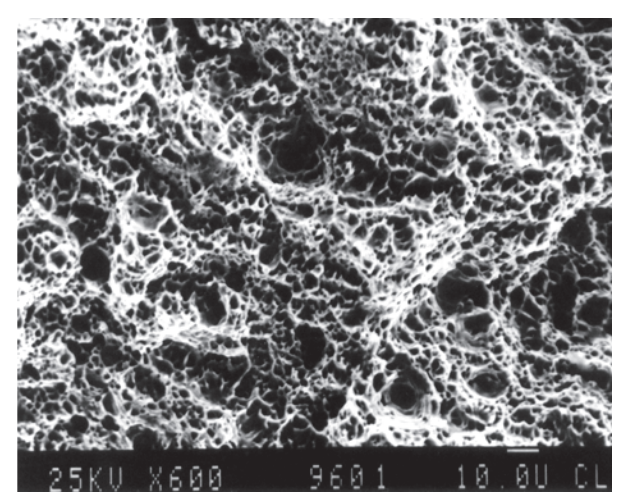

(b)

FIGURE 9: Fracture surface. (a) C16E after creep exposition at $450^{\circ} \mathrm{C}, 7120 \mathrm{~h}$; (b) $\mathrm{H} 300 \mathrm{LAD}$ after creep exposition at $450^{\circ} \mathrm{C}, 8930 \mathrm{~h}$.

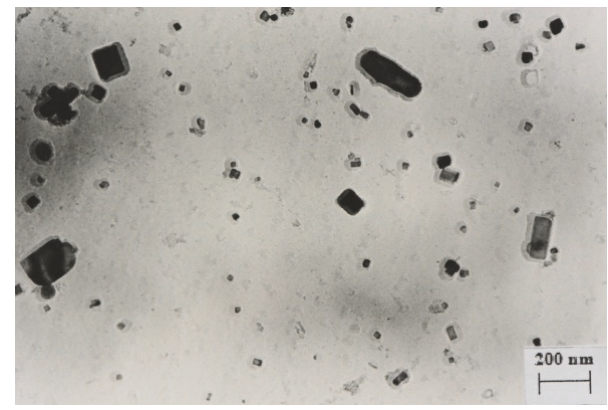

(a)

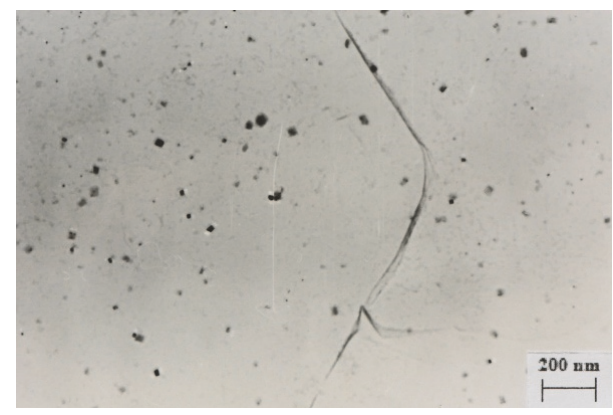

(b)

Figure 10: Substructure of (a) H300LAD and (b) H380LAD.

fractures are formed, and, at longer fracture times, the fractures can be considered brittle. The fractures of C16E steel have a cup characteristic, up to the time to fracture of $10^{4}$ hours. A crucial influence on the heat resistance of microalloyed steels is the contribution of precipitation.

(ii) The creep limit $\left(R_{m T} 10^{4}\right)$ of microalloyed steels, up to $500^{\circ} \mathrm{C}$, is higher than that of C16E steel.

(iii) On the basis of these test results and analyses, it can be stated that microalloyed steels can be well used to construct power equipment that works at elevated temperatures of up to $500^{\circ} \mathrm{C}$.

A limitation of this research was the small number of test materials due to the time and energy intensity.

After the completion of the research, the studied materials were used for shields that prevent the escape of heat while protecting a pipeline against the adverse effects of high temperatures. Our experience shows that H380LAD is suitable for use, up to a temperature of $500^{\circ} \mathrm{C}$, for the abovementioned application in constructing power equipment.

\section{Conflicts of Interest}

The authors declare that there are no conflicts of interest regarding the publication of this paper.

\section{Authors' Contributions}

Mária Mihaliková conceived and designed the study; Mária Mihaliková and Anna Lišková performed the experiments and analyzed the data; Kristína Zgodavová performed the theoretical analysis. All authors read and approved the manuscript.

\section{Acknowledgments}

This paper was developed within two projects supported by the Ministry of Education, Science, Research and Sport of the Slovak Republic: VEGA 1/0549/14 "The analysis of local properties of automotive steel in dynamic conditions" and VEGA 1/0904/16 "The utilization of processes capability and performance and products dimensional tolerances in the management of material consumption and related economic, energy and environmental consequences (MINIMAX-3E).”

\section{References}

[1] J. Michel, M. Buršák, and I. Mamuzić, "Creep properties of microalloyed steels," Metalurgija, vol. 41, no. 2, pp. 71-76, 2002.

[2] C. Chen, H. Yen, F. Kao et al., "Precipitation hardening of high-strength low-alloy steels by nanometer-sized carbides," Materials Science and Engineering: A, vol. 499, no. 1-2, pp. 162$166,2009$. 
[3] W. Yan, W. Wang, Y. Shan, K. Yang, and W. Sha, "Creep of Heat-Resistant Steels," in 9-12Cr Heat-Resistant Steels, Engineering Materials, pp. 163-189, Springer International Publishing, Cham, Switzerland, 2015.

[4] H. G. Svoboda and H. C. Nadale, "Fatigue Life of GMAW and PAW Welding Joints of Boron Microalloyed Steels," Procedia Materials Science, vol. 9, pp. 419-427, 2015.

[5] M. Pirinen, The Effects of Welding Heat Input on the Usability of High Strength Steels in Welded Structures [Ph.D. Thesis], Acta Universitatis Lappeenrantaensis 514, Lappeenranta University of Technology, Lappeenranta, Finland, 2013.

[6] Natoli Free Whitepaper: Steel Quality. Retrieved from Natoli Engineering Company, Inc., Available online: https://natoli .com/about/steel-quality/ (12th December 2016).

[7] M. Cabibbo, A. Fabrizi, M. Merlin, and G. L. Garagnani, "Effect of thermo-mechanical treatments on the microstructure of micro-alloyed low-carbon steels," Journal of Materials Science, vol. 43, no. 21, pp. 6857-6865, 2008.

[8] E. P. Degarmo, J. T. Black, and R. A. Kohser, Materials and Processes in Manufacturing, Wiley, Hoboken, NJ, USA, 11 edition, 2011.

[9] ISO 6892-1:2009 Metallic materials - Tensile testing Part 1: Method of test at room temperature, Geneva, Switzerland, 2009.

[10] ISO 6892-1:2011 Metallic materials - Tensile testing Part 2: Method of test at elevated temperature, Geneva, Switzerland, 2011.

[11] X. Xiao, G. Liu, B. Hu, J. Wang, and W. Ma, "Microstructure Stability of V and Ta Microalloyed 12\%Cr Reduced Activation Ferrite/Martensite Steel during Long-term Aging at $650^{\circ} \mathrm{C}$," Journal of Materials Science and Technology, vol. 31, no. 3, pp. 311-319, 2015.

[12] A. Raj, B. Goswami, and A. K. Ray, "Perspectives of creep and fatigue behavior in microalloyed steel," Journal of Metallurgy and Materials Science, vol. 54, no. 2, pp. 93-110, 2012.

[13] M. Mihaliková, V. Girman, and A. Lišková, "Static and dynamic tensile characteristics of S420 and if steel sheets," Materiali in Tehnologije, vol. 50, no. 4, pp. 543-546, 2016.

[14] Y. Xu and S. Song, "Impurity antimony-induced creep property deterioration and its suppression by rare earth ceriumfor a $9 \mathrm{Cr}-$ 1 Mo ferritic heat-resistant steel," Metals, vol. 6, no. 8, article no. 187, 2016.

[15] D. Nakhaie, P. Hosseini Benhangi, M. Mazinani, F. Fazeli, and M. R. G. Ferdowsi, "Thermomechanical processing of a Nbmicroalloyed steel in a controlled-forging treatment," Advanced Materials Research, vol. 409, pp. 835-840, 2012.

[16] ISO 204:2009, Metallic materials - Uniaxial creep testing in tension - Method of test, 2009.

[17] I. Tylek and K. Kuchta, "Mechanical Properties of Structural Stainless Steels," Technical Transactions, vol. 4, pp. 60-79, 2014.

[18] C. Wen, T. Xu, and K. Guan, "Correlation factor study of small punch creep test and its life prediction," Materials, vol. 9, no. 10, article no. 796, 2016.

[19] A. Raj, B. Goswami, and A. K. Ray, "Creep and fatigue behavior in micro-alloyed steels - A review," High Temperature Materials and Processes, vol. 33, no. 1, pp. 1-12, 2014.

[20] I. M. Nowak, H. E. Evans, B. J. Connolly, D. Flahaut, and Z. Zhang, "Origins of tertiary creep in microalloyed $25 \mathrm{Cr}-35 \mathrm{Ni}$ centrifugally cast alloy tubes," Materials at High Temperatures, vol. 31, no. 3, pp. 191-197, 2014.

[21] M. Mihaliková, M. Német, and M. Vojtko, "IF steel effect of rate deformation on the fracture surface change," Key Engineering Materials, vol. 635, pp. 118-121, 2015.
[22] D. Liu, D. J. Pons, and E.-H. Wong, "The unified creep-fatigue equation for stainless steel 316," Metals, vol. 6, no. 9, article no. 219,2016

[23] G. González, R. Molina, M. Delavalle, and L. Moro, "Variation of Creep Resistance in Ferritic Steels by a Heat Treatment," Procedia Materials Science, vol. 9, pp. 412-418, 2015. 

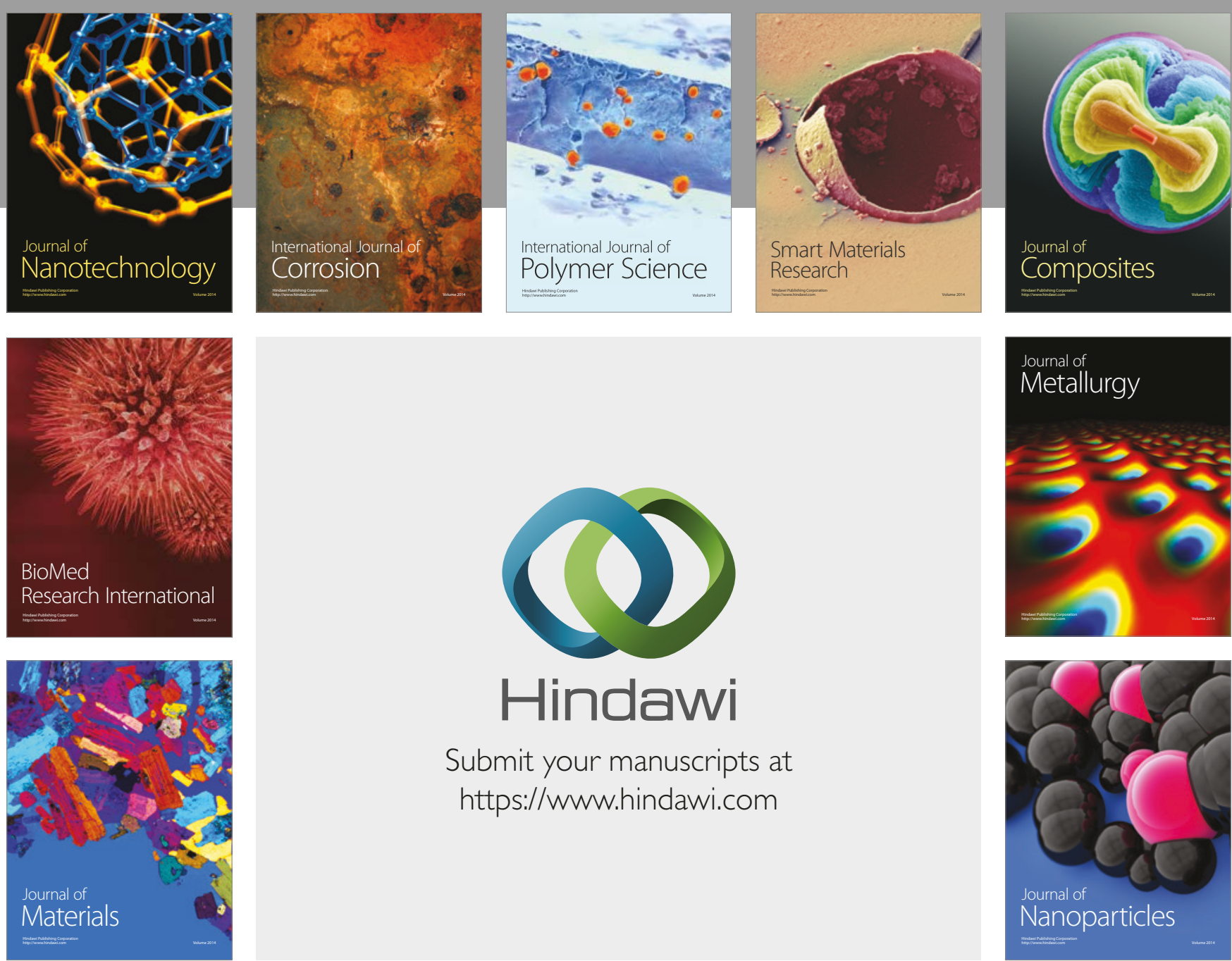

\section{Hindawi}

Submit your manuscripts at

https://www.hindawi.com
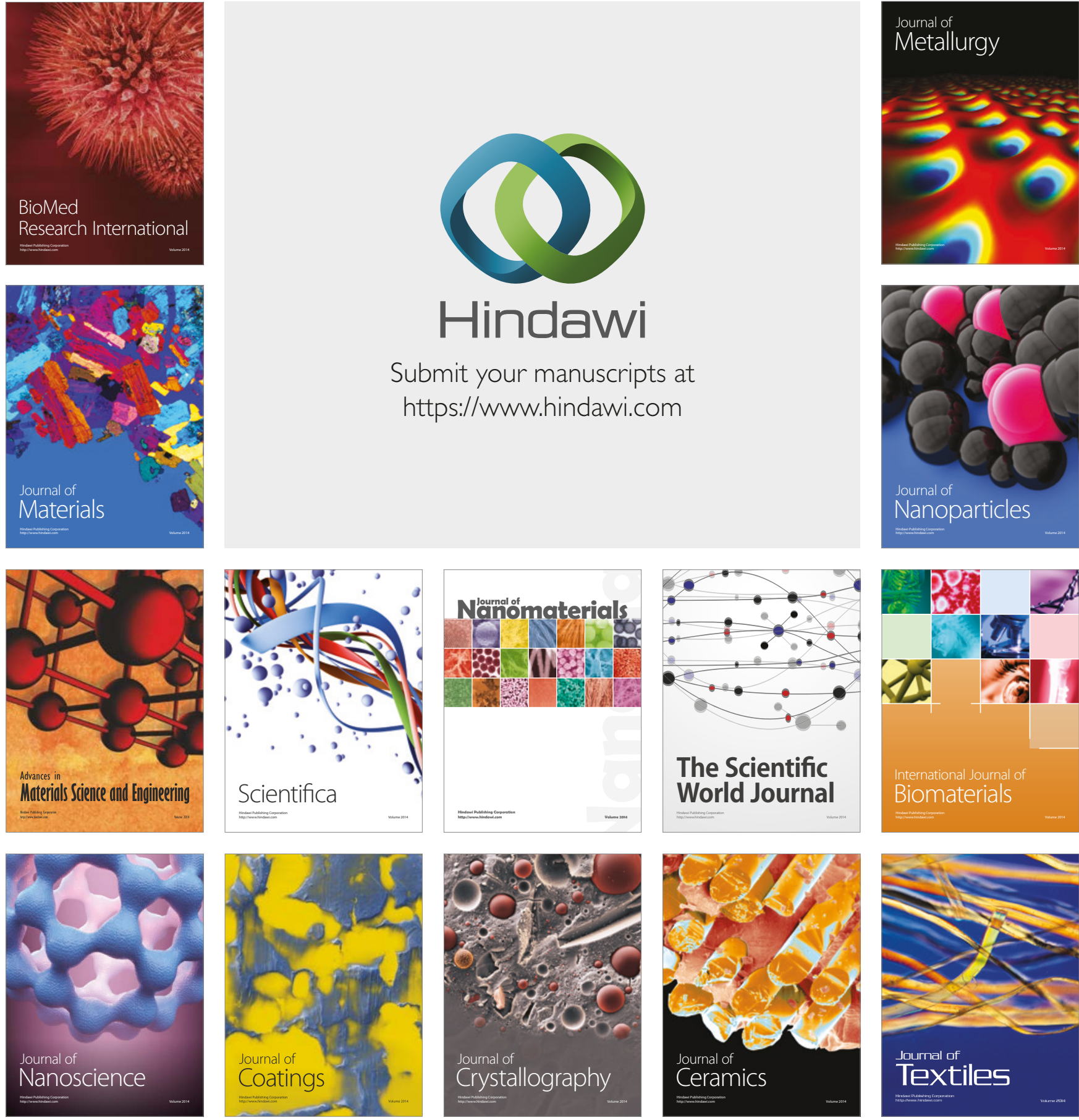

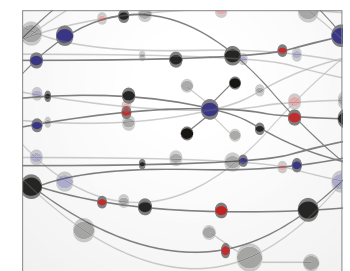

The Scientific World Journal
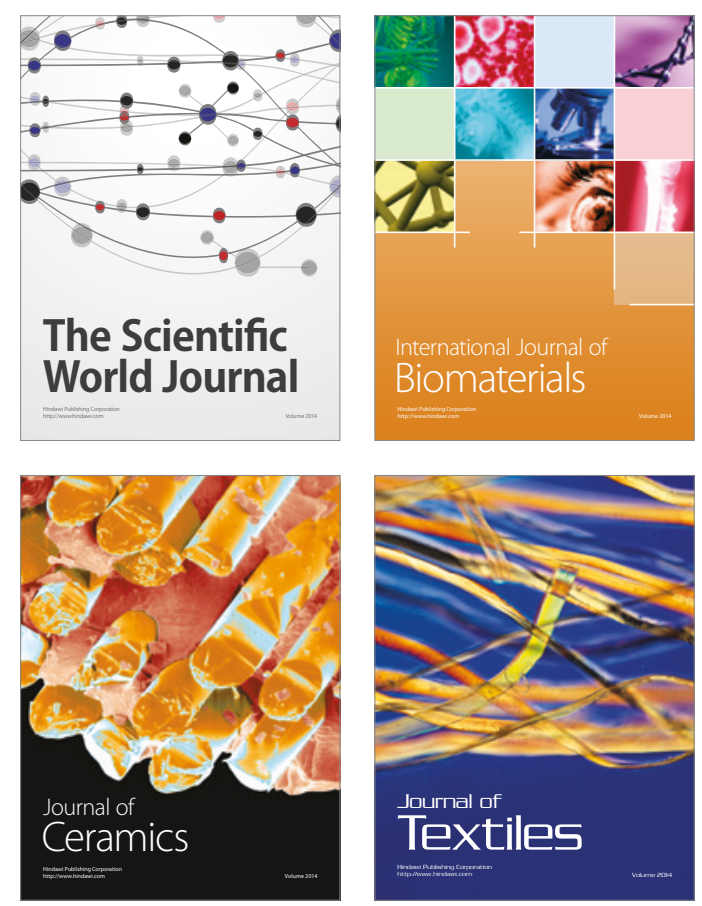